\section{Amniotic Fluid Embolism}

British Medical fournal, 1970, 1, 545

Little progress has been made in elucidating the aetiology of amniotic fluid embolism since it was described by Steiner and Lushbaugh (1941). They wrote: "Profound shock coming on suddenly and unexpectedly in a woman who is in unusually severe labour, or has just finished such a labour, especially if she is an elderly multipara with an excessively large, perhaps dead, fetus with meconium in the amniotic fluid, should lead to a suspicion of this possibility ... If pulmonary oedema now develops quickly in the known absence of previously existing heart disease, the diagnosis is reasonably certain."

Apart from the occurrence of coagulation failure and its treatment, nothing has been added to this statement since it was written, and there has been no advance in treatment. The outcome is still determined more by the severity of the embolism than by the efficiency of the attending medical personnel.

It is difficult to assess the incidence of this condition, but it ranks among the commoner causes of death in labour and immediately afterwards.

The Department of Health and Social Security (1969) stated that "in the present state of our knowledge the occurrence of amniotic fluid embolism is both unpredictable and unpreventable." On surveying the reported deaths in the literature it was noted that a number of patients died with unruptured membranes-that is, forewaters-at or near full dilatation of the cervix, and awaiting the delivery of a second twin. The following is such a case, and it is postulated that the situation is avoidable.

\section{CASE HISTORY}

The patient was a healthy 44-year-old para $6+0$. Her previous pregnancies and deliveries had been uneventful. She was admitted to hospital at 36 weeks with mild pre-eclamptic toxaemia which settled. She was finally admitted at 38 weeks in early labour. She had hydramnios, and her girth was $47 \mathrm{in.}(118 \mathrm{~cm}$.). The vertex was presenting, but not engaged. The blood pressure was $130 / 80$. Labour progressed satisfactorily, and she was transferred to the Labour Ward when the cervix was four finger breadths dilated. She was sitting up and well, and her contractions were fair to strong, occurring once every four minutes. She suddenly became cyanosed, had a convulsion, and collapsed. An airway was immediately inserted, oxygen administered, and the cardiac team summoned. Despite positive-pressure oxygen she remained cyanosed and pulseless. She was unconscious, and anaesthetic agents were not used. Two intravenous drips were instituted, and emergency blood was transfused under pressure. On vaginal examination the cervix was fully dilated, and the membranes were intact and bulging. Artificial rupture of the membranes was performed, which released a large quantity of bloody liquor, described by the operator as "pure blood."

An immediate internal podalic version and breech extraction was performed, and a stillborn male infant weighing $8 \mathrm{lb} .6 \mathrm{oz}$. $(3,800$ g.) delivered. The placenta was immediately removed. There was no retro-placental clot. Bleeding was profuse, and ergometrine 1 mg. was given intravenously. The uterus was explored. It was intact and empty, but completely atonic. Bimanual compression of the uterus, and compression of the aorta against the spinal column, did not control the bleeding. The blood was not clotting, and $4 \mathrm{~g}$. of fibrinogen was given while the uterus was packed tightly.
Twenty-seven minutes after the initial collapse no heart sounds were audible, and the E.C.G. complexes were recorded with external cardiac massage only. Attempts to resuscitate the patient continued, and bicarbonate $4.2 \% 250 \mathrm{ml}$., aminocaproic acid $8 \mathrm{mg}$, hydrocortisone $200 \mathrm{mg}$., Syntocinon 20 units, aprotinin 50,000 units, and calcium gluconate $20 \mathrm{ml}$. of $10 \%$ solution were given intravenously together with 12 pints (6.8 litres) of blood. Attempts at cardiac stimulation remained unsuccessful, and resuscitation ceased 72 minutes after the initial attack.

At necropsy the uterus was intact and all the organs appeared natural. The placenta was diffusely haemorrhagic, but there were no blood clots. Histological examination of the lungs showed "amniotic squames and some meconium in many pulmonary vessels."

\section{COMMENT}

Labour progressed normally, with intact membranes up to full dilatation of the cervix. She then sustained severe amniotic embolism. At that time she was not draining liquor and there was no vaginal bleeding, but when the bulging forewaters were artificially ruptured a large quantity of bloody liquor was released. In the absence of vaginal bleeding and a perforated uterus, the blood could have gained access to the liquor only at the placental margin.

Suggested Cause.-During labour the uterine effort is directed towards achieving dilatation of the cervix. At full dilatation it is directed towards expulsion of the products of conception aided by maternal effort. While the membranes are intact the pressure is distributed evenly over their entire surface. If the membranes or "forewaters" do not rupture the contracting fundus will try to expel the entire sac, with its contents. The membranes containing the presenting part will slide downwards in the vagina towards the vulva. The uterus cannot expel the baby from the intact sac, and neither can it expel the sac, because it is anchored by the placenta. The membranes are then likely to tear at the margin of the placenta, which is their only fixed point allowing blood to gain access to the liquor, and allowing the liquor, now under high pressure, to gain access to the placental bed. This results in amniotic fluid embolism.

It is suggested that this was the cause of the embolism in the present case. During delivery of a second twin excessive delay in rupturing the membranes, especially in the presence of strong contractions, creates a similar situation. It is not suggested that this is a common cause of amniotic fluid embolism or that embolism is inevitable, but that its likelihood is increased.

I should like to thank Mr. Arthur Williams for his help and permission to publish this case.

\section{Louis D. Courtney, M.B., M.R.C.o.G., M.A.O., Registrar Obstetrics and Gynaecology, Radcliffe Infirmary, Oxford.}

\section{REFERENCES}

Brown, M. S. (1965). West Virginia Medical fournal, 61, 75.

Department of Health and Social Security (1969). Report on Confidential Enquiries into Maternal Deaths in England and Wales 1964 1966, p. 83. London, H.M.S.O.

Dlhos, E. (1963). Ceskoslovenská Gynekologie, 28, 44.

Maternal Mortality Committee (1967). Fournal of the Irish Medical As-

sociation, 61, 400.
Steiner, P. E., and Lushbaugh, C. C. (1941). Journal of the American Medical Association, 117, 1245, 1340. 